\title{
Hablar, entre el ser y el pensar
}

\begin{abstract}
$\underline{\text { Joan Rué* }}$
Leal, A. (2020). Pensar el pensamiento. Editorial Octaedro.

"En la forma que tenemos de usar las palabras se halla incrustada una teoría del espacio y del tiempo", afirma Steve Pinker (2007) en su prólogo a El mundo de las palabras. Aprendemos el lenguaje y su empleo en un medio social a lo largo de innumerables procesos de interacción social, de ahí que el modo y el contexto donde lo empleamos contenga implícita también una teoría de las relaciones sociales y de cómo nos situamos ante los demás. Desde unas relaciones de poder, por ejemplo, Francia acaba de legislar la prohibición de discriminar a alguien por su acento regional, y es precisamente desde presupuestos y prejuicios como estos que los humanos realizamos nuestro aprendizaje comunicativo, nuestras actitudes y nuestro propio pensamiento.

Este es el trasfondo de la aportación que Aurora Leal realiza en su reciente obra Pensar el pensamiento. En este trabajo, la autora, psicóloga y docente retirada de la Universidad Autónoma de Barcelona, y especializada en el desarrollo del pensamiento en interacciones sociales, nos propone un muy relevante aporte sobre cómo "el recurso a un lenguaje u otro implica - o da lugar a - una u otra forma de pensar, de organizar nuestro mundo, nuestro pensamiento" (p. 25).

“Tienes cinco vacas y pierdes dos. ¿Qué ocurre?”, era una de las preguntas realizadas a los niños de Manhattan cuando se validaba el test de inteligencia wISC. Con el mismo propósito se les preguntó también lo mismo a los niños de un medio deprimido, en los montes Apalaches, en el estado de Nueva York. "Me quedan tres", respondían los primeros. "No volvería a casa hasta encontrarlas, pues mi padre me..." decían los segundos. Esta anécdota muestra cómo a partir de un mismo enunciado - que creemos neutro-, las respuestas difieren a causa de la percepción del propio ser social-en-el-mundo, y atendiendo a las respectivas estrategias de pensamiento-en-acción. De este modo, puede decirse que se aprende a hablar y a emplear el lenguaje aprendiendo a estar y a ser, a la vez que se aprende a pensar.

Aurora Leal se interroga acerca de cómo elaboramos nuestras propias ideas, y a partir de esto elabora un análisis sobre la doble expresión - gráfica y corporal — de una idea determinada por parte de un grupo de sujetos universitarios, así como de los momentos en los que dicha expresión se desarrolla entre los participantes en una determinada interacción. La idea nuclear de esta investigación era "el respeto en la pareja". A partir de esta noción, se trataba de analizar los valores subyacentes al respeto, el modo en que se reconoce al otro, y la escucha. El motivo para dicha selección fueron los contenidos implícitos en las relaciones personales cotidianas.

Para el proceso de observación y de análisis, la autora asumió tres enfoques de fondo, complementarios entre sí: lo que hacen los participantes en la interacción propuesta, lo que piensan, y la expresión de lo que sienten. En otros términos, abordó acción, pensamiento y emoción en las relaciones cotidianas. A partir de ello, el análisis de las observaciones pone de relieve los diversos significados culturales asociados a aquella idea de respeto, así como el sentido particular que puede asignarle cada individuo. Así, su corolario permite responder a las preguntas sobre cómo se construyen las ideas y cómo nos hacemos conscientes de lo que sabemos y de lo que pensamos.

Para el desarrollo de su investigación, la autora sintetiza el corpus que le permitirá sustentar su trabajo y validar su aproximación al problema de partida. Así, elabora su aproximación a la relación entre lenguaje y pensamiento sobre las representaciones de las ideas y la exteriorización del pensar, del hacer y del sentir, desde un enfoque holístico y con el construccionismo social como referente.

Posteriormente, la segunda parte de la obra nos sitúa en la perspectiva de cómo los sujetos han desarrollado sus propias aproximaciones a la noción de las relaciones personales en acción a partir del proceso de reflexión sobre el respeto, el reconocimiento y la escucha en la interacción social; una reflexión realizada a partir de elaboraciones gráficas - como dibujos y esquemas-, así como del lenguaje empleado en
\end{abstract}

\footnotetext{
Pedagogo. Universitat Autònoma de Barcelona. Profesor retirado. joan.rue@uab.cat
} 
las situaciones creadas. Tal vez lo más relevante de este trabajo sea la compleja metodología reflexiva propuesta a los sujetos, pues esta permite evidenciar cómo de una idea aparentemente simple y al alcance de todo el mundo se puede derivar un rico metaconocimiento respecto a cómo pensamos y nos pensamos a nosotros mismos en-acción con los demás.

El análisis realizado y sus alcances le permiten sostener a su autora que, frente al hipotético uniformismo de los resultados esperados en cualquier aprendizaje, cada sujeto progresa desde sus propias apreciaciones iniciales, sin que aquellos acaben siendo necesariamente idénticos.
Finalmente, en oposición a los paradigmas disciplinarios y al paradigma del rendimiento, la autora nos propone que "el autoconocimiento del propio saber debería formar parte de la educación" (p. 121). En definitiva, fomentar metodologías reflexivas - como la referenciada - en la educación de profesionales de la formación sería la conclusión necesaria de toda lectura atenta de la obra comentada.

\section{Referencias}

Pinker, S. (2007). El mundo de las palabras: Una introducción a la naturaleza humana. Editorial Planeta. 